\title{
CAREER AND COLLEGE READINESS FOR GRADES P-1: EXPOSURE AND AWARENESS
}

\section{INTRODUCTION}

At a research university, in a graduate-level research course in education, students were asked by a guest lecturer, "At what age should career counseling and education begin?" The students (who represented a wide range of fields, including higher education, curriculum and instruction, and educational leadership) voted and overwhelmingly said either late high school (junior and senior year) or in the first year of college. Out of a class of 23, only two of the graduate students indicated that elementary school was the appropriate time to begin such exploration. It was apparent that the majority of graduate students in the course knew little about the developmental nature of career and college readiness for $\mathrm{P}-12$ students. In this chapter, we explore the early elementary years and how career and college education can positively impact academic success and open postsecondary options, even for very young students.

\section{CAREER AND COLLEGE READINESS FOR PREK, KINDERGARTEN, AND FIRST GRADE}

The American School Counselor Association's (ASCA's) National Model (2019), ASCA Mindsets and Behaviors (2021), and federal initiatives such as the National Math and Science Initiative (2017) and the Every Student Succeeds Act (Executive Office of the President, 2015) all underscore the importance of career and college readiness for all students. Historically, attention to career and college readiness for students in PreK, kindergarten, and first grade has been limited, as schools have concentrated mainly on late adolescence and high school, yet studies show that young children can understand careers and need career education in order to connect academics to the world of work. Development of career and college readiness skills, such as critical thinking and problem solving, begins early in life as well. In this chapter, readers will note that we focus more on career development than on college exploration. Young children need to have a foundation for understanding what careers are and how the school day and workday are alike, an understanding of their interests, and a connection between what they are learning in school and the world of work before making links to postsecondary expectations. We advocate building that base in $\mathrm{P}-1$ and allowing students to familiarize themselves with the language of careers before introducing how careers relate to postsecondary training options. 
In this chapter, we use Gottfredson's (1981) career theory and Young's (1983) ecosystemic career development concepts to illustrate how school counselors can design practical and fun career and college readiness activities for PreK, $\mathrm{K}$, and first-grade students. Additionally, we explore stakeholder education related to career and college readiness for parents, teachers, and community partners. Using developmentally appropriate play techniques and student competencies, we examine how to effectively design and implement PreK, K, and first-grade career and college readiness activities for classroom counseling as well as gradelevel activities.

\section{DEVELOPMENTAL OVERVIEW}

In order to effectively implement career and college readiness education and counseling in PreK, $\mathrm{K}$, and first grade, it is important to consider the overall development of children at those grade levels. What follows is a general overview of child development and how each area of development connects to career growth. Please note that this overview is general and may not apply to every child.

\section{Psychosocial and Socioemotional Development}

According to Erikson (1963), children between the ages of 3 and 5 are in the psychosocial stage known as initiative versus guilt. During this time, the main psychosocial task is to actively explore the environment and to develop a sense of control over physical surroundings. Therefore, children in this age group are very active, inquisitive, and because of their natural curiosity, they are always learning (Hupert, 2018). In early elementary, students begin to engage with other children through play, although much of their play is still side-to-side rather than face-to-face play (particularly in PreK), and the major influence in the life of children in this age group is predominantly the family unit.

Around the transition period from kindergarten to first grade, children begin to enter the stage of industry versus inferiority (Erikson, 1963). The focus in this stage is on children learning and mastering academic tasks; students are continually learning new information and, particularly in today's educational environment, are tested to demonstrate their competence. Students who excel at tasks gain self-confidence while those who do not often develop feelings of inferiority (e.g., poor self-concept). These positive and negative feelings might affect future career and college outcomes as well as overall self-esteem. Teachers and counselors may begin to notice some children in PreK, $\mathrm{K}$, and first grade starting to have negative thoughts about themselves, having doubts about their likability or attractiveness, or worrying that they are not smart enough. Self-esteem may be built through helping children have success experiences and assisting them in recognizing their unique strengths. 
During the early elementary years, two major feelings develop that contribute to socioemotional development: shame and guilt. Shame comes from feeling humiliated, while guilt comes from feeling badly about hurting another person (Belsky, 2019). While shame can foster unhealthy socioemotional development, guilt may be essential to ensure that children learn that other peoples' feelings matter. Learning to care about the feelings of others, but not be consumed by focusing on others, is an important skill. Further, Belsky (2019) identified an orientation toward prosocial tendencies as an important part of socioemotional development. Prosocial behavior is behavior motivated by the intention of helping another person rather than oneself (Ding et al., 2018). Prosocial behaviors may include comforting others, assisting others, using manners, donating, sharing, engaging in cooperative work or play, exhibiting kindness, and displaying empathy (Belsky, 2019; Ding et al., 2018). Such behaviors are largely formed during early childhood years. In the context of career and college readiness, socioemotional maturity is a critical element for developing effective relationships in college and in the workplace (The Collaborative for Academic, Social, and Emotional Learning [CASEL], 2016).

CASEL (2016) defined social emotional learning (SEL) as the process by which children gain "the knowledge, attitudes, and skills necessary to understand and manage emotions, set and achieve positive goals, feel and show empathy for others, establish and maintain positive relationships, and make responsible decisions" (p. 2). CASEL (2016) noted that SEL improves the future career, business, and economic outcomes for students by building competence in five key areas: (a) self-awareness, (b) self-management, (c) social awareness, (d) relationship skills, and (e) responsible decision-making. Beginning in early elementary, students start to gain competence in these areas. By viewing students' misbehavior as opportunities to learn and grow in each of these areas rather than punishable offenses, educators help students develop a growth mindset on how to adjust their own behavior and how to learn from mistakes. One of the most prominent SEL tasks in early elementary is self-management, and in particular, emotion regulation. As students gain greater personal agency, they learn how to better manage their emotional responses to the environment (Belsky, 2019).

According to Belsky (2019), emotional regulation includes learning to manage feelings and deal appropriately with emotions-neither having externalizing (e.g., inappropriate outbursts, fighting, demanding, controlling behaviors, or acting out aggressively toward others) nor internalizing (e.g., timidity, self-consciousness, unmanageable anxiety) tendencies. Children with emotional regulatory capacities display balanced emotion that is appropriately expressed given their circumstances. So, a child with positive emotional regulation skills who falls down may cry but is consolable and, once comforted, resumes normal activities. Conversely, a child with poor emotional regulation skills who falls down may cry but might also get up and, in a fit of rage, hit others who are nearby or blame others for falling down. Emotion regulation is important for success in both career and college because of 
the need to get along with others in collaborative group work as well as deal with stress, anxiety, and conflict.

However, one final caveat about emotional regulation is noteworthy. Perry et al. (2018) conducted an 8-year longitudinal study beginning when children were 2 years old and concluding when they were 10 years old. They also met with the families at an interim point when the children were 5 years old. The researchers were investigating over controlling parenting and emotion regulation in children. They used a sample of 422 racially and economically diverse children but found the results were steady: parents who were over controlling when children were 2 years old had children who were poor emotion regulators by the time the children were 5 . These same children struggled significantly socially, emotionally, and academically by the time they were 10 . Other researchers have found that helicopter parenting correlates with poor self-management, fewer coping skills, lower coping efficacy (Odenweller et al., 2014), depression and anxiety (Wenze et al., 2019). Thus, it appears that parenting style plays a role in students' ability to regulate emotion, and school counselors may want to consider sharing ways that parents can help children to develop independence and autonomy.

\section{Cognitive Development}

According to Piaget (1977), children in PreK, K, and first grade are generally in the cognitive stage of development known as preoperational thought. During this stage, children have difficulty conceptualizing time (such as the future) and, therefore, may have difficulty projecting what their future lives may be like, including considering what careers they may want. This does not mean, however, that they can't think about and learn about careers and college.

Children in this stage generally do not display logical, linear thought and are often very egocentric. Egocentrism in regard to preoperational thought refers to children's lack of understanding that other people have worldviews or perspectives that differ from their own (Piaget, 1977). Children in the preoperational stage may display thought influenced by fantasy, or magical thinking, and can have some difficulty discerning what is real or not.

Learning for children in the preoperational stage of cognitive development requires that adults delivering instruction are excellent scaffolders, meaning that they break down content into smaller, more manageable pieces of information, give students lots of opportunities to practice what is learned in order to achieve mastery, and allow students an opportunity to engage in practical application of learned material through models such as the gradual release framework (i.e., I do, we do, you do). This model involves demonstration of a new skill by an adult, followed by group practice of the skill together, and then students attempting the newly learned skill on their own (Castagno-Dysart et al., 2019).

Additionally, Vygotsky (1978) contended that children use a working memory where they actively process information based on prior learning or discard 
information that is not necessary to remember. Adults may help children improve their memory capacities by incorporating activities that involve repetition and practice. These skills are highly necessary for future academic success.

Children may begin problem-based learning (PBL) at this age and their natural curiosity lends to this type of learning. PBL involves a student-centered approach where students generate questions about a topic and direct the learning process. Social interaction and collaboration are key components of this pedagogical approach (Yew \& Goh, 2016). Moreover, with time, students exposed to PBL appear to see value in their work and the connection between what they learn in school and the world of work (Virtue \& Hinnant-Crawford, 2019). Although most studies of PBL focus on secondary and post-secondary learners, students can begin learning to be autonomous thinkers and using problem-based strategies at an early age. When they do, results appear to be positive.

For example, Suswandari et al. (2020) conducted an experimental study of elementary students using PBL. For students in the experimental group (PBL) there was a significant improvement in social skills over the control group (non-PBL condition). With regard to academic development, Rehmat and Hartley (2020) conducted a study of elementary students' understanding of engineering content and critical thinking when using PBL strategies. Students in the experimental condition (PBL) had significant gains in knowledge of STEM (engineering) content and critical thinking skills over students in the control (non-PBL) condition.

Here is an example of PBL in a kindergarten class from a unit on space. Prior to starting the unit, the teacher asked students to write down every question they had about space. A sample of questions produced by the students included: Why does the moon change shape? Are stars and planets the same? What is a comet? Is the sun bigger than earth? The teacher built her unit around the students' questions and gave a copy of the questions to the school counselor. During the unit, the students made a model of the phases of the moon. They worked collaboratively to design classroom constellations and to name them. They also worked together in the school parking lot to draw a scaled, chalk model of the solar system. The school counselor presented a lesson on space careers (astronauts, engineers, and astromedicine). The teacher sent home a list of science concepts students would be studying at school over a 2-week-period related to space to answer a list of questions generated by students. At the conclusion of the 2 weeks, students brought in a model of a moon station they created where people could live and work based on what they had learned about space and space careers. They had to address a problem in their model (e.g., How can scientists exercise on the moon? How can food be grown on the moon?). Other considerations for addressing the learning needs of young children include using contextual learning strategies (e.g., using examples that are familiar to students) and providing interactive and experiential learning opportunities where students can manipulate and interact with objects and tap into their need for fantasy and creative play. Counselors can be most effective when they meet students where they are developmentally, starting with 
familiar concepts, then exposing them to new ideas through activities that allow them to discover. Overall, students at this age are very active learners. Career play is very appropriate and can easily be integrated in classroom career instruction. We explore play techniques later in this chapter.

\section{Moral Development}

According to Kohlberg (1981), most children in PreK, K, and first grade are in the preconventional stage of moral development and, therefore, judge actions as either right or wrong based on the consequences of the action. In short, if the person committing the action gets punished, then students in this stage of development might assume the action was wrong. Two forces of thought are predominant in preconventional moral development: (a) obedience and punishment characterized by deference and respect to authorities, and (b) self-interest-driven behavior characterized by behavior that benefits the self. For this reason, students at this age are impressionable and may show interest mainly in careers held by their parents, teachers, and other adults they want to please rather than based on career knowledge or exploration. Therefore, careers that are reinforced by family and respected adults will often be parroted by children as the career they want. It is typical to hear children say they want to be a doctor, lawyer, football player, president, or whatever career is most esteemed in their circle of support.

Students in grades PreK-1st grade are also vulnerable to integrating judgments about careers and college based on the perspectives of family or other adults. Indeed, according to Kohlberg (1981), children in this developmental period have an orientation to obedience and make choices based on what is denoted as right and wrong from the authorities in their lives. For instance, it is very common for students at this age to tattle on their peers if they see them breaking a rule. Likewise, they may have very rigid beliefs about which careers and postsecondary educational options are acceptable and which are not. I, the first author, was presenting a career lesson at an elementary school when one of the Kindergarten children asked me if I was "educated." I asked her what she thought "educated" meant and she said, "I'm asking if you went to college or not." I told her I did and then asked her how come she was curious about my education. She simply replied, "Because you need to go to college." I am certain this is a message she had received from people she trusted. In her mind, going to college was important, even if she wasn't sure what it meant or what a degree was; what is important is that someone was discussing this with her and had impressed upon her a value about education, specifically college education. Similarly, students might categorize careers as "good" or "bad"-for example, being a police officer may be perceived as a "good" career and being a sanitation worker may be perceived as a "bad" career based on judgments students have internalized from their families or from gender and socialization based on education or values. Conversely, being a police officer may be seen as "bad" if students' families perceive the police as oppressive or unjust. 


\section{Gender}

In early elementary school, children's preoperational cognitive development leads to a tendency to categorize people, including by gender. In PreK, K, and first grade, students have very concrete views of what men and women should look like, how they should act, and what roles are appropriate. Much of this comes from socialization in the family where children are often given sex-typed toys and their parents or guardians treat them in sex-typed ways. For example, girls may be given play dishes, a kitchen set, and a doll for gifts, whereas boys may receive tools, cars or trucks, and building blocks. This type of gender socialization can have a lasting impact throughout the lifespan.

By early elementary school, many students have begun to primarily play with same-sex friends, have received gender-type reinforcement from family members, and understand that their sex is a permanent characteristic (cannot be changed by chance). These differences manifest in play and school through common behavior patterns; in general, girls are more collaborative while boys are more competitive, girls are usually calmer while boys experience greater excitability, and boys seek group dominance in play while girls display nurturance (Belsky, 2019). Finally, gender matters in career decision-making for early elementary students. In the next section, we review Gottfredson's theory and just how predominant sex typing is in the career development of children.

\section{RELEVANT CAREER THEORY FOR PREK, K, AND FIRST-GRADE STUDENTS: GOTTFREDSON (1981) AND YOUNG (1983)}

\section{Gottfredson's Theory of Circumscription and Compromise}

Historically, school systems have introduced career and college readiness activities for students in high school. This approach is problematic, according to Gottfredson's (1981) theory, because children and adolescents have already begun circumscribing (i.e., narrowing) their career options since early elementary school. Support for Gottfredson's theory came from a study of elementary children conducted by Auger et al. (2005), where they found that by fifth grade, many students had already circumscribed their career aspirations and self-limited their career options. Indeed, it appears that circumscription begins around the age of six. This finding underscores the need to continually work on broadening students' understanding of career and existing postsecondary options throughout P-12 education. In this chapter, we focus on Stage 1: Orientation to Size and Power and Stage 2: Orientation to Sex Roles, as these are the predominant stages of career development for children in grades PreK-1. 
According to Sharf (2013), Gottfredson's Stage 1: Orientation to Size and Power refers to how children begin to understand that their world is different from the world of adults. They realize that there are limits to what they can do because of their size and power; for example, a child may see that his father owns a lawn care company where he has to run lawn equipment, such as lawn mowers, weed eaters, and edgers. The child realizes that the work his father does takes strength and height that the child does not have. Although the child understands that the tools used for lawn care are part of the father's work, the child also believes that he is too small or weak to do that type of work.

As children get chronologically older (around the age of 6), they enter Stage 2: Orientation to Sex Roles. As this occurs, they begin to develop a strong sense of sex-typing, which dictates the careers children believe are tolerable for girls and the careers that are tolerable for boys. This boundary can be very definitive, and adults must be intentional and deliberate in order to challenge sex-type assumptions. We explore this stage more fully in Chapter 8 as it affects second and third graders comprehensively.

In spite of children's career assumptions, there is reason for optimism, according to Gottfredson $(1981,2002)$. Specifically, she noted that children may be encouraged to reconsider their career choices when given formative new experiences that challenge career sex types. When school counselors understand how to do this effectively, they may increase students' perceptions of possible career options.

\section{Young's Career Concepts}

In a National Poverty Center report, Rodems and Schaefer (2019) contended that $38.4 \%$ of children in the United States currently have "at least one form of material hardship such as food insecurity, inability to pay essential household bills, inability to access medical care due to cost, or substandard and overcrowded housing" (p. 1). With this in mind, school counselors have to consider how the systems in which children live may affect their understanding of careers and college. Students living in poverty may have fewer opportunities for exploring academic interests or exposure to events and places that stimulate future career and college decision-making processes. For example, students living in poverty may not have access to museums, galleries, or travel. Young (1983) asserted that an ecosystemic approach to career development was critical, and this may be especially true for elementary school students, as their parents and teachers are so influential in their lives. Additionally, teachers and parents may not have received career or college education as children themselves, and therefore, may be unsure of how they can help their early elementary school-aged children explore careers or colleges. Thus, considering how to engage teachers and parents within the scope of a comprehensive school counseling program to promote career and college readiness is important, and we address this concern more fully later in this chapter. 
Beyond considering Gottfredson's and Young's work with small children, school counselors will benefit from having an understanding of how to integrate play techniques in career and college education for elementary students as part of the fun in the career and college readiness curriculum. Through curriculum that supports students in becoming good classroom citizens, using study, homework, and test-taking skills to be academically successful, and promoting creativity, safety and motivation, school counselors encourage students to build efficacy as leaders and learners. The school counseling curriculum should be broad, energizing, and engaging for P-1 students, and school counselors need to remember the incredible value of play for the experience of learning with this age group.

\section{PLAY TECHNIQUES AND CAREER AND COLLEGE EXPOSURE FOR P-1 STUDENTS}

Play is the natural language of children and is the manner in which children communicate (Landreth, 2012). It is used by children to explore and experiment; therefore, it is a critical learning tool and part of the process by which children can understand their own thoughts, feelings, ideas, and behaviors (2012). Play also is a means for promoting formative cognitive and social development, helping children develop skills such as creativity, imagination, exploration, and the development of complex symbolism (Gastaldi et al., 2019). As children age, play provides them opportunities to develop greater social interaction skills through imitation, conflict resolution, and constructive dialogue with friends (2019).

According to Zosh et al. (2018), it is important to note that play occurs on a spectrum and may range from self-directed, free play initiated by children to adult-directed structured play and games. All types of play can produce growth and developmental change for children. Through the manipulation of play materials, children practice new behavior, problem solve, take the role of leader, and feel empowered to engage the world around them (Kottman \& Meany-Walen, 2016). Additionally, children use play to understand and explore the functions of objects in their environment (2016). For instance, when playing with building blocks (e.g., Legos, Tinker Toys, or Lincoln Logs) children learn about building and construction. Similarly, children playing with tools and a tool bench become oriented to the functions of those tools as they begin to explore how they are used in the real world (e.g., a hammer is used for pounding). Using play techniques to engage children might help adults in schools develop relationships through establishing mutual positive affect, reacting with warmth and empathy, conveying caring and nurturance, and developing rapport through eye contact and verbal and nonverbal behaviors (2016). Therefore, play is a very functional approach for school counselors to use in teaching young children, particularly PreK, $\mathrm{K}$, and first-grade students, about career, college, and real-world success skills. 
Some might ask if play therapy should be used by school counselors. And if so, what kinds of play? Structured? Guided? Unstructured? There are many uses of play therapy, yet not all types of play therapy may be appropriate for elementary school settings due to the nature of the environment and the intended use in learning. In this chapter, we are focusing on large-group, structured, and directed play in PreK to first-grade classrooms for the purpose of engaging students in learning about careers. Stone (2017) contended that schools have become over-reliant on teaching by a sole medium-worksheets with written goals, and many students find this medium disengaging. Conversely, Zosh et al. (2018) underscored the usefulness of structured, guided play in early childhood learning citing that research has demonstrated children learn best when material is introduced to students in active, engaging, meaningful, socially interactive, joyful, and iterative means (i.e., construction of new knowledge). Structured play provides such a pedagogy for career development in early elementary for school counselors. Although elementary school counselors may have received some training in play techniques in their graduate programs, they are not required to be registered play therapists and most do not have advanced training in play therapy techniques. Thus, the interventions we discuss in the following require little specific training and could be reasonably and ethically initiated by most school counselors. We review some basic principles of play as they relate to career exploration.

\section{The Nature of Play and Learning}

According to Landreth (2012), play allows children to take risks through imagination, a key benefit of the fantasy nature of play. In terms of careers and college, children are allowed to explore possibilities through the creativity and autonomy afforded in play in spite of the realities in which they live. Applied to careers, children may choose to explore the world of an astronaut (space toys), an archeologist (dinosaurs and digging), or a safari guide (toy animals and vehicles) even if these opportunities are not accessible through their home or immediate surroundings. Equally important, during play, children might choose to step out of expected gender roles; girls may be construction workers and boys may be cooks and caregivers. This exact realm of play, fantasy, and exploration might be the initial way in which career circumscription (Gottfredson, 1981) can be combatted for very young children (grades PreK-1). Children are able to experience new roles such as doctor, a scientist, or president without the reminders of social stigma, gender roles, or low social expectations. Truly, children may be free to explore the careers they wish to explore if school counselors and teachers create the expectation that play is autonomous. Explorative play can be integrated in the classroom through the use of career centers where students have access to dress-up and play items associated with careers. Students may visit these centers when they have completed their classwork and during structured breaks. 
Play may also be integrated in the core counseling curriculum. Ericksonian play therapy (named after Milton Erickson) uses an approach that may be particularly helpful in schools due to the limited amount of time the school counselor has in each classroom. In the Ericksonian approach, two layers of communication are occurring, known as parallel communication or refraction (Marvasti, 1997). We will use puppets as the medium to illustrate the concept. In this type of play, the counselor introduces children to a metaphorical problem similar to a child's own problem or issue needing resolution. In regard to career, in order to promote career awareness and decision-making self-efficacy, a school counselor may introduce a puppet to children during a classroom lesson. In the following case, this activity is used at the culmination of a classroom unit on careers to help students with application of prior knowledge. The puppet's dilemma is that she doesn't know about careers and so the students will be teaching the puppet what they have learned and will help the puppet make career decisions. In doing so, the students' learning will be reinforced, resolving confusion about careers and career decision-making. Exhibit 7.1 gives an example of the use of puppets as a play technique with a group of kindergarten students.

\section{THE SCHOOL COUNSELOR AND THE CORE COUNSELING CURRICULUM}

During PreK, K, and first grade there are some essential career, academic, and social/ emotional skills that are vital for postsecondary success. Most importantly, many students may not know anything about what careers or college are or even have a language to discuss careers or college in PreK. The core counseling curriculum should focus on the major tasks of beginning to understand and explore careers. By the end of first grade, students should be able to (a) recognize careers and how they are different from jobs, (b) identify community helpers, (c) use basic career language, (d) demonstrate positive attitudes toward self, others, and school, and (e) recognize the tools, clothing, and vehicles used for work within specific occupations (Curry, 2017). Additionally, when students have been given opportunities to learn about careers in PreK and kindergarten, they are often ready to learn about tools of the trade for careers. For example, students may start to recognize typical patterns of tools such as doctors use stethoscopes, firefighters use a water hose, musicians use instruments and sheet music, and carpenters use hammers and saws. By the end of first grade they may be able to understand that people use different tools to perform specific work, that work occurs in a variety of locations, and that various types of occupations require different clothes (i.e., a nurse wears scrubs). They also might be introduced to the idea that people might need to spend more time in school in order to become a doctor or a firefighter or a musician-introducing the concept of college.

Helping students achieve these competencies is critical to early academic and career development and should be guided by the school counselor who has expertise 


\section{EXHIBIT 7.1}

\section{AN EXAMPLE OF REFRACTION IN A KINDERGARTEN CLASSROOM CAREER LESSON}

Counselor: Okay, students, today I have a very special guest for you to meet. Her name is Sally. (Counselor holds up puppet.) Oh, no! Sally looks sad. (Puppet is slouching, looking down.) Sally, what's wrong?

Puppet: In my class, my teacher said we are going to be learning about careers, but I don't know what a career is.

Counselor: Sally, the students in this class have also been learning about careers. Maybe the students would like to help you. Students, would you like to help Sally? (Students say yes-loudly.)

Puppet: Oh, thank you so much. (Sally looks up.)

Counselor: Great. Okay, who can tell Sally what a career is?

Student 1: It's like something you want to do when you grow up. Kind of like work only you plan to do it.

Counselor: Thank you, something you do when you grow up, something planned.

Student 2: And you are trained to do something. You might go to college or be trained by someone to do a career.

Student 3: Ummm ... my dad . . . works in an office. And my mom works at a school as a teacher. Those are their careers.

Student 4: It's work you like to do.

Counselor: Thank you all. Sally, does that help?

Sally: I think I understand that career is something that a person chooses and plans to do, it requires training beyond school, and it is something that a person likes and wants to do. Is that right?

Students: Yes!

Sally: But I don't know what I want to be when I grow up! I don't even know what choices I have!

Counselor: Well, Sally, that's okay. Many girls and boys are unsure of what they want to be when they grow up. Students, how many of you are unsure of what you want to be? (Some students raise hands.)

Puppet: Golly! I thought I was the only one!

Counselor: Students, what have we discussed about careers that might help Sally?

Student Responses: Careers in your neighborhood.

Counselor: Good answer! Yes, we talked about community helpers. What were some examples of community helpers?

Student Responses: Mail carrier, firefighter, police officer, day-care worker.

Counselor: Well, these students are great listeners, Sally, because we did talk about all of those. What other types of career things have we talked about this year?

Students: Your family's careers. What your mom or your granny or your uncles and people like that do ... what their career is. We also talked about our likes and dislikes. 


\section{EXHIBIT 7.1}

\section{AN EXAMPLE OF REFRACTION IN A KINDERGARTEN CLASSROOM CAREER LESSON (continued)}

Counselor: Oh my! I can tell you all have been really listening. I definitely think we can help. Sally, let's start by talking about the careers you see in your neighborhood. . .

By helping the puppet (Sally), students integrate and apply prior career learning and also use the career language they are developing (Pellegrini, 1984). The material the students suggest to the counselor to help Sally solidifies salient information they have acquired, it also demonstrates that they are thinking through developmentally appropriate strategies for career decision-making, a skill they are just starting to learn and a key piece of developing career maturity. Through a fun and engaging activity, the counselor is helping the students use what they know to resolve a parallel problem: helping Sally learn about careers.

Counselors may also use play in early childhood education to allow students to explore a career. An example of this happened when a group of PreK teachers and the school counselor took PreK students to the local fire department for a tour and fire safety tips at the end of a unit on community helpers. The students were all given plastic fire safety helmets and honorary firefighter badges. The children were given 20 minutes of playtime in the field area beside the firehouse to play the role of firefighters with the real firefighters. Through the use of an obstacle course and their new gear, the students were guided through a simulated fire field where they got the chance to experience the role of firefighters, regardless of gender. A digital photograph of each child was taken and printed at school on a sheet of paper that said: "What I learned about firefighters." Each child was assisted by their teacher and teacher's aide in writing a sentence about what they learned at the firehouse. In this way, students were integrating imitative role-play (playing the firefighter) and symbolic meaning (words to describe what they learned) in order to continue to develop a lexicon for career with a conscious understanding of career roles (Pellegrini, 1984). At the end of the day each child was sent home with a fire safety coloring and workbook for their families with instructions for parents about talking to their child about fire safety in their home, how to call 911, and community helper careers.

in these areas. School counselors need to be strategic given that their time in the classroom is limited. Each lesson should be methodically planned, evidence or research based, goal-oriented, and designed with specific outcomes in mind. In P-1, much of the career and college exposure is done in the classroom setting or through the creation and cultivation of a career and college-bound culture. Moreover, an effective school counseling program involves collecting data to demonstrate that these things are happening.

In order to demonstrate program effectiveness, it is important that school counselors consider how they will assess student learning outcomes, and they will need to be flexible when choosing methods for assessment with $\mathrm{P}-1$ learners because of early elementary students' disparate levels of reading comprehension. Counselors also must 
be creative to ensure that they accurately assess student knowledge in developmentally appropriate ways, such as through matching and other recognition activities. For instance, by the end of first grade, students can realistically understand the tools that go with specific occupations. Imagine that a school counselor had written the following outcome objective for a lesson on "Tools of the Trade": At the completion of this lesson, $80 \%$ of first-grade students will be able to accurately match tools to specific occupations four out of five times. For the lesson, the school counselor has 30 toy tools (e.g., plastic hammer). After explaining tools of the trade, the school counselor hangs pictures of careers around the room. Students are placed in dyads and are given two or three "tools" per dyad. They are asked to place their tools by the careers they match. Next, the school counselor and the students discuss each picture, which tools match each picture, and how the tools are used in each specific career. Examples might include a hairdryer for a hairstylist, a rolling pin for a baker, a stethoscope for a doctor, and so on. After the lesson, the school counselor could give the students a worksheet with five pictures of occupations being performed (i.e., teacher, firefighter, doctor, construction worker, and artist). Opposite of the occupations are pictures of five instruments (i.e., hammer, water hose, paint palette, stethoscope, and chalk). Students are asked to draw a line from the "tool" to the matching career. The school counselor is assessing whether or not $80 \%$ of students can get four out of five correct to assess student learning for this activity, so they may collect the students' assessments and calculate the percent of correct answers. The data gathered is meant to help the school counselor assess whether or not students understood the lesson content rather than to give a score, or grade, for the students' work. The school counselor is simply assessing whether or not, as a whole, students were able to match tools and careers. The Voices from the Field feature gives an example of one school counselor's career curriculum development for kindergarten and first grade.

As you see in the Voices from the Field, a lot of thought, planning, organization, and assessment is done when developing and providing classroom lessons. From the onset, the school counselor must have lesson objectives, some ideas about what students in her school know based on culture and geography, a sense of the students' developmental abilities, and some creative ideas for engaging students during classroom presentations. So far, she has been able to demonstrate some impressive outcomes. However, implementing the career and college readiness curriculum in P-12 schools is not the sole responsibility of the school counselor. Following, we discuss the important roles that various stakeholders play in students' career and college readiness development even as early as PreK.

\section{IMPORTANCE OF STAKEHOLDERS}

Parents/guardians, extended family members, and other adults are highly influential in the lives of PreK, K, and first-grade students. Helping stakeholders develop awareness and knowledge of careers can foster positive communication and interaction about careers between children and their families. Through collaboration 
and consultation, providing faculty in-service training, offering parent workshops, and developing a comprehensive career and college readiness curriculum, school counselors are well positioned to assist stakeholders in becoming more aware of the needs of their children/students as well as the roles they all can play in helping students become exposed to and more aware of careers and college.

\section{Stopping the Dream Squasher}

Adults often have the inclination to promote what they perceive to be realistic career and college options for children rather than allowing children to simply explore. In other words, they may intervene to stop students from imagining or discussing careers or postsecondary educational options that they perceive as being difficult to attain or undesirable in some way. For example, the first author was at a family's home when their 6-year-old son brought out a play guitar and began strumming and screaming "I'm a rock star!!! Yeah, yeah, yeah . . . I’m a rock star!!!" The father laughed and said, "I hope not, that means you'll be starving or eating cans of ravioli for the rest of your life." Most of the adults in the room laughed at the father's joking cliché about the starving artist. However, it is important for parents to realize that a natural interest their child may have could be linked to many careers, and that within career clusters there may be many lucrative careers and opportunities for gainful employment. Although the child in this example may not have had a true aspiration to be a rock star (he was simply playing at the time), there is room to discuss careers even in the context of ordinary play. For example, careers in the music industry go well beyond rock star to include music producers, technicians, talent scouts, signing agents for record labels, videographers, promoters, and disc jockeys, among others. Helping parents expand their vocabulary and understanding of careers gives them a common language to discuss careers with their children. Also, providing concrete examples of the subtle and not-so-subtle ways they might squash their children's dreams may encourage them to monitor their reactions.

A similar scenario happened with the first author (an elementary school counselor at the time) and a first-grade teacher. The teacher had students in her classroom write down on a piece of paper what they wanted to be when they grew up. Five of the boys in the class wrote down "football player" (it may be contextually important to note that this occurred the week of the Super Bowl). The teacher was frustrated and began to tell the class what a poor career choice football is and how most people don't become professional athletes. The teacher came to the counselor later and shared her frustration and exasperation about what she perceived to be students' poor choices. The first author then encouraged the teacher to help students explore related areas of work to professional sports, including sports journalists, reporters, physical therapists, marketers, trainers, coaches, sports agents, and others. By assisting the teacher in understanding how to link students' interests with a broader range of career opportunities, the author was hopefully able to intervene against future incidents of dream squashing! 


\section{VOICES FROM THE FIELD \\ EARLY ELEMENTARY CAREER EXPOSURE}

Meghan Birch, PLPC

School Counselor, Dorseyville Elementary School

I am a school counselor at an elementary school in a low socioeconomic, rural area. There are 377 students from PreK-sixth grade that attend my school. The demographics are $92 \%$ African American, $7 \%$ White, and $1 \%$ Hispanic, and $100 \%$ of our students are on free lunch. Because my students are from a low socioeconomic background, most have limited exposure to career options. With the support of my administration, I am able to implement a comprehensive career and college readiness program in grades $\mathrm{K}-6$. Although there are benefits to teaching career lessons in each grade, I especially enjoy working with the lower grades because of the opportunity to broaden the range of career options these students consider. I will give an overview here of typical career lessons in my kindergarten and first-grade classes.

A good starting point with kindergarten is simply to expose them to a variety of careers. I am often surprised by their limited knowledge of career options. I usually begin the first lesson by asking students to name different careers they have seen in their families. Student responses typically vary between local fast-food restaurants and convenience stores in the area, which seem to indicate a limited exposure to careers or misunderstanding of the definition of career. I want to begin in kindergarten to expand their understanding of a career and how they can decide which career paths interest them.

All students seem to love puppets, especially the younger ones (although I am always surprised at how excited my fifth and sixth graders get about puppets!). I introduce my kindergarten classroom lessons using an entertaining pair of puppets representing a police officer and chef. The puppets keep the children engaged and add an extra element of fun. From the carpet, students interact with the puppets as they discuss their careers with each other and the class. The puppets ask the class questions about their classroom jobs and start to help students define "career" as a combination of what you enjoy doing (interest) and what you are good at (skill/aptitude). Each puppet talks about his career and how his interests and skills match his career. At the kindergarten level, I wrestle with whether students are ready to understand these complex topics, but I have found value in introducing this concept early. Knowing that some students may not be ready to grasp this abstract definition, I revisit this topic in my first-grade lessons.

Kindergarten students often have the misconception that a person should not have dislikes. I want students to understand that it is important to be aware of likes, as well as dislikes, in exploring career options. Many kindergartners think that you must like, or pretend to like, every activity. The puppets help me to address this misconception through their dialogue. One puppet will say he doesn't like something - usually eliciting a gasp or laugh from the students - and the other puppet will explain that it is okay to have likes and dislikes. I use the puppets to explain the importance of knowing what you dislike in order to decide what careers are best for you. 


\section{VOICES FROM THE FIELD}

\section{EARLY ELEMENTARY CAREER EXPOSURE (continued)}

After our time on the carpet, students complete a worksheet with four quadrants on which they draw pictures of their favorite activities at school and at home and their least favorite activities at school and at home. In reviewing students' work samples, I am looking for student work that represents likes and dislikes appropriately and reveals a beginning understanding of these preferences.

In subsequent lessons with kindergarten students, we discuss how careers are different, but all important. I use a book such as the LMNO Peas, a career read-aloud, to talk about a variety of careers and how they are useful. There are many follow-up activity sheets from this book involving letters of the alphabet and careers that begin with each letter. In these work samples, I reinforce students who choose to include previously unfamiliar careers in their responses. The career learning goals for the series of kindergarten lesson are: (a) to understand that the word career refers to activities that combine skills and interests, (b) to identify likes, dislikes, and skills that can help you choose a career, and (c) to understand that all careers are important in some way. I am also reinforcing classroom literacy skills (academics) through the use of reading and writing.

With first graders, I start to introduce the idea of career clusters. I use a simplified four career cluster approach: careers outside/working with animals, careers working with technology, careers making things, and careers working with people. In second grade, the clusters are narrowed into six categories, and then by third grade I begin to introduce the full 16 career clusters. Ideally, I like to come to each first-grade class for three lessons. In the first lesson I introduce the concept of a career as being more than a job, involving training, skills, and interests. Defining and identifying skills and interests can be an entire lesson in itself depending on the level of the students. Next, I introduce the four career clusters, usually through a presentation with plenty of pictures and a handout to go along. We discuss examples of careers in each cluster and I ask them to think about the clusters that best fit their skills and interests.

Once the students seem to have an understanding of the career clusters, we play a matching game using a poster at the front of the room, divided into four quadrants containing each of the four career clusters. Using cards with the names of different careers, I call on students one at a time to place a career card in the correct cluster. Students love participating in the activity and helping their classmates choose the correct cluster. The activity also provides an extra incentive for students to stay engaged during the presentation in order to participate in the activity afterwards. The learning goals of my first-grade career lessons are: (a) to define career (as a combination of skills, interests, and training), (b) identify the four broad career clusters, and (c) to categorize careers within those clusters. I typically use a short assessment at the end of the series of lessons in which students are asked to place careers from a word bank into one of the four career clusters. By the end of the first-grade career lessons, typically $80 \%$ to $90 \%$ of the students are able to match careers with the appropriate cluster. 
A wonderful activity to teach family members is how to do a community career interview. This skill helps them avoid dream squashing while simultaneously encouraging them to become career explorers alongside their children. The skill is fairly easy to acquire and can be taught through newsletters, social media, family workshops, Parent Teacher Organization meetings (PTO), the school counselor's website, or family meetings. Basically, school counselors teach family members how to interview community members in their places of work (Curry, 2017). While the family is shopping, visiting the library, getting an oil change and so on, parents or family members ask career questions and encourage children to do the same. Questions might include: (a) What is your favorite thing about your work? (b) What is something about your work that might surprise people? (c) What have you learned about yourself from this job? (d) What was your favorite subject in school and how did it prepare you for this job?

Other families may choose to integrate career ideas in other ways, such as by allowing students to "try on" careers at home. For example, instead of inviting children to help a parent cook dinner, invite them to try being a baker or a chef. Other household examples might include asking children to try being a gardener, a painter or artist, a photographer, and so forth. A perfect example may come during holidays. Instead of asking children to help decorate the home, ask them if they would like to be a home designer. The change in language reflects the opportunity to try on a career. Family members can then ask their children how they liked the career (Curry, 2017).

\section{Working With Teachers to Integrate Career and College Information in Classroom Curriculum}

Teachers play an integral role in student academic and career development. To begin, teachers influence students' understanding of how classroom instruction relates to careers and the world of work, provide meaningful learning opportunities for students both in and out of the classroom, and influence the positive work habits and attitudes students develop (Curry et al., 2013). Yet, many teachers may not have received training in how to integrate career or college content into their existing curriculum, so we begin by discussing career and college faculty in-service for early elementary teachers.

\section{Faculty In-Service for Early Elementary Teachers}

When teachers are asked to integrate career and college information in the education curriculum, they may feel hesitant due to the overwhelming demands placed on them already from high-stakes testing and other measures of accountability. However, when school counselors demonstrate that integrating career and college information is a natural adjunct to the existing curriculum and does not require an 
extraordinary amount of time, teachers may be more open. Illustrating the infusion of career and college content for teachers is critical and may be done through faculty in-service programs, team meetings, or one-on-one consultations. Sample faculty in-service activities might include identifying quality guest speakers for career or college topics, finding out about careers and colleges through technology (e.g., demonstrating $\mathrm{O}^{*} \mathrm{Net}$ and the Occupational Outlook Handbook online), connecting classroom content to the world of work or college majors, or providing information about science, technology, engineering, and mathematics (STEM) careers and STEM content, and so forth. One faculty in-service focusing more on critical thinking and problem-solving skills that is valuable to teachers of all levels (elementary, middle, and high) is Design Model Thinking.

Design Model Thinking (DMT) is a five-step process for solving complex problems, although some models include additional steps (Interaction Design Foundation, n.d.). The five steps are (a) empathize, (b) define, (c) ideate, (d) prototype, and (e) test. The first step, empathize, is meant to have students truly empathize with individuals who may have a major problem. For example, telling students "There is a town with dirty water and it is making a lot of people very sick. Imagine if you drank water in your own home in your town and it made you sick and you could not go to school or your parents could not go to work because the water made them sick. How might you feel?" Students empathize and consider how the problem would feel for people living with the problem. The second step, define, allows students to apply content learned in their classes. For the problem above, students might consider: what would cause the water to become dirty? The students would discuss many possibilities for the problem. Next, they would work in their groups to ideate, or problem solve solutions to fix the problem. In this phase, all solutions are on the table and none are cut for any reason. Following the ideation phase, students would design a prototype, or a model, of a solution to fix the problem they are addressing. A key component of this stage is that it is experimental and often students find flaws in their design or their designs fail at this stage. Students may also identify meaningful ways to improve their designs during the prototype stage. The final stage, test, involves having the design evaluated by someone outside of the group.

DMT has been shown to have a positive effect on students because it promotes critical thinking and also allows them to experience failure in a situation where mistakes are expected and accepted (Riddle, 2016). Further, DMT gives students an opportunity to practice generating solutions to real world challenges through application of content learned as well as social emotional skills (2016). Preliminary studies in elementary schools in Austria, Switzerland, and Germany demonstrated that exposure to DMT helped students retain creativity and promoted collaboration and independent learning. Additionally, students demonstrated motivation and open mindedness for these techniques (Hogsdal \& Grundmeier, 2019) (see Exhibit 7.2). 


\section{EXHIBIT 7.2}

\section{INTERVIEW WITH PATRICIA QUINONES}

The benefits of Design Model Thinking (DMT) were expressed in a 2017 interview with assistant superintendent Patricia Quinones of St. Vrain, Colorado school district. Her district pursued DMT after noticing that although students generally tested well, they were stagnating. Students' test scores had plateaued and they didn't seem to be improving in their critical thinking, problem solving, creativity, and communication skills. In response, the district opened an innovation academy and trained all faculty on DMT. They also committed to teaching all students design thinking beginning in kindergarten. Children were brought into large maker-style rooms and given real world problems to solve in fun and engaging ways. For example, in one lesson, elementary children were read a book called, Bat Baby Finds a Home, by Robert Quackenbush. In the book, the bat family have great difficulty finding a home because places are too loud or are unsafe (i.e., the real world issue for bats). A discussion of why bats are so important to the environment ensued after the book was read. After, students followed the five steps of DMT and designed their own bat homes. Quinones emphasized the importance of having students fully follow the five steps before developing and testing their prototype, as although the last two steps might be more fun, the first three steps are critical to helping them develop problem-solving and critical thinking skills.

\section{Meaningful Academic Opportunities That Promote Careers}

Beginning early in their school careers, students need to understand how the content they are learning is related to the world of work. By giving students opportunities to practice hands-on learning, teachers promote student understanding of what they can do with what they are learning. School counselors should encourage teachers to do this and explain why it is helpful. One important way to do this is to develop community partnerships so that students have career development support from professionals and workers in the community. For example, at one elementary school, the school counselor and first-grade teaching team collaborated on a science unit on weather. The students learned about weather patterns, seasonal changes, temperature readings, and precipitation. At the end of the unit, the school counselor arranged for a field trip to the local news channel (community partner) where students met a meteorologist and learned about hurricanes. Later, when they came back to school, they drew weather pictures and set up their own weather lab in the classroom where they did daily precipitation and temperature readings, noted the weather patterns and changes, and used the Internet to record the 3-day weather outlook. Each morning, one student played weather reporter and gave the results to the class, giving each child a chance to practice the role of meteorologist. Exhibit 7.3 gives another example of an activity that links academic content and career education. 


\section{EXHIBIT 7.3}

\section{SAMPLE ACTIVITY TO CONNECT ACADEMIC CONTENT AND CAREER LEARNING OPPORTUNITY}

During a health sciences unit, the kindergarten classes at Great Oaks Primary were given information on personal hygiene (e.g., the importance of proper handwashing). As one of the unit lessons, the kindergarten teachers and school counselor collaborated to have a dentist and a dental hygienist (community partners) come to the school to talk about the importance of brushing and flossing teeth. The dentist brought models of human teeth and demonstrated the correct way to brush teeth and the students practiced brushing the models' teeth using toothbrushes provided by the dentist. During the presentation the dentist and dental hygienist explained what they do each day at work. They described how they work together and what their individual roles are when a patient comes for a visit; additionally, they showed the students the types of tools they use to do their jobs. They also told the students what they can expect if they come to the dentist to get their teeth cleaned. At the end of the day each student was given a bag containing a coloring book about going to the dentist, a letter home to parents about what they had learned about oral hygiene and dental careers, a small tube of toothpaste, a child-size toothbrush, and a sample of dental floss.

\section{Parent Engagement Activities}

As previously mentioned, parents play a critical role in students' exposure to careers and college. Fortunately, there are many ways to engage parents in career and college-related activities in the early elementary years. In this section, we focus on practical strategies for including parents and assisting them in career and college education and curriculum, including communicating with parents about careers and college, financial literacy training, and school-based activities that promote learning and career (see Exhibit 7.3).

\section{Communicating With Parents About Careers and College}

Developing a culture of career and college readiness in the school begins with including parents. Communicating about careers and college and suggesting home-based strategies for career and college exploration (e.g., pull out pictures of where you went to college and share stories with your children) are critical roles for school counselors. A comprehensive approach to disseminating this type of information may be best for communicating with parents. For example, many school counselors have websites and use social media, but given the current poverty and unemployment rates in the country, a substantial number of parents may not have a computer or Internet access. Those who do not may miss out on important information if it is only disseminated online. School counselors should not 
underestimate the power of sharing information in partnership with organizations such as churches, community centers, and Boys \& Girls Clubs.

\section{Financial Literacy Training}

Financial literacy is crucial for children's postsecondary success, whether they attend college or not. Learning to manage a budget, save money, and plan for financial difficulties are crucial skills to lifelong financial health and stability. Many parents may be in need of information either to manage their own finances, to help teach their children learn how to manage money, or to know what options they have to save for their children's future. As an outreach activity, schools can partner with a local bank or credit union to offer free educational workshops on all of those topics.

At one elementary school, the school counselor has an account manager from a local credit union speak at a parent night once a year. The account manager also comes to the school once per semester and parents can schedule time to talk one-on-one during that time about long-term college savings plans. By conveying the importance of thinking and planning ahead, school counselors may help families realize their children can have more opportunities than they initially thought. During one such meeting, a family shared a unique strategy for saving money. The family was going through a lot of financial difficulty (father lost his job) and the family was living on just the mother's income. So, each week, the parents had their children cut coupons from the newspaper, and for each coupon used, the family put the saved money into a college fund. Opportunities such as parent workshops can allow families to share their creative ideas for saving. Another family shared that they have an annual family garage sale, and the money they make is used for extra college savings for their children.

\section{Including Parents in School-Based Career and College Awareness Activities}

Just as students need a common language to discuss careers and college, helping parents develop the language of careers and college can promote communication at home. Offering a workshop on the importance of career and college awareness for young children would allow school counselors to provide parents with relevant information and language. Moreover, by creating opportunities for parents to participate in learning activities with their children, school counselors and teachers can model how to integrate career and college information into learning activities and can deliver important career and college concepts to both children and their parents. Exhibit 7.4 provides a sample parent-student activity that illustrates a way to promote student learning and career awareness. 


\section{EXHIBIT 7.4}

\section{SAMPLE FIRST GRADER-PARENT ACTIVITY}

At Windy Hills Elementary, the first-grade teaching team developed a classroom unit on plant science. Students learned about the differences between flowers, plants, vegetables, and trees. They also learned about the conditions plants need to live: soil with nutrients, water, and sunlight.

At the end of the unit, parents were invited to participate with their children in a plant science night at the school. Funding for the night was provided by a local Lowe's Home Improvement store (community partner) and the Parent-Teacher Association at Windy Hills. Parents and children first met in their child's classroom for a 10-minute review on plant science. Afterward, each family was asked to go out into the school yard and pick five different leaves. They brought the leaves to the gym where tables were set up so that the leaves could be sorted by categories: oak, palm, maple, grass, and so on. Students learned that all trees have unique leaves. At each table a teacher or teacher's aide helped them categorize their leaves and talked about what the tree does for the leaf and what the leaf does for the tree.

After the leaf collection and category activity, parents and students sat in the bleachers as the school counselor showed a quick video with pictures and descriptions of careers related to plants (gardener, lawn care worker, greens keeper, farmer, and horticulturist). Parents and children then went to the cafeteria where displays were set up. The displays were designed by and set up by fifth-grade students. Each display had a picture of a type of plant and a career. For example, one display had a picture of a farmer with a wheat crop. Each child who visited that display received a wheat cracker. The next display had a farmer with an orchard, and each child visiting received a slice of apple. The next was a picture of farm hands picking walnuts (students each got a walnut to taste). In all, 30 displays that demonstrated a plant and a plant career were set up. Not all had food; for example, the greens keeper display had a miniature golf hole (borrowed from a local mini golf course!).

At the end of the night, courtesy of Lowe's Home Improvement store, each student and parent were given a small pack of flower seeds and a small plastic pot. Instructions were given on how to grow them, and families were sent home to begin their own plant science experiment. This family science night did not cost the school or families any money and was well received by all who attended.

\section{SUMMARY}

In this chapter, we have highlighted career and college awareness opportunities specifically for PreK, K, and first-grade students. As elaborated, students in this age group are beginning to explore the world around them through play and interaction with other students, teachers, parents, and counselors. This is an essential time to intervene, as students are influenced by their social environments 
and are developing their own conceptions of their strengths and limitations applied to careers and college. In particular, we reviewed Gottfredson's first two career development stages and examined the integration of play techniques in career and college curriculum. We continue to look at the role of the school counselor and the development of students' career and college awareness in Chapter 8 with a focus on second and third grade.

\section{TEST YOUR KNOWLEDGE}

1. In what ways do problem-based learning and design model thinking promote career, academic, and social emotional learning in early elementary students?

2. In what ways have you seen children play out careers?

3. What keeps parents or teachers from helping PreK to grade 1 children explore careers or colleges?

\section{KEY REFERENCES}

Only key references appear in the print edition. The full reference list appears in the digital product found on http://connect.springerpub.com/content/book/978-0-8261-8674-4/ch04

Auger, R. W., Blackhurst, A. E., \& Wahl, K. H. (2005). The development of elementary aged children's career aspirations and expectations. Professional School Counseling, 8(4), 322-329. http://www.jstor.org/stable/42732626

Curry, J. (2017). Elementary career counseling: Promising practices and effective strategies. The School Counselor, 55(2), 10-18.

Odenweller, K. G., Booth-Butterfield, M., \& Weber, K. (2014). Investigating helicopter parenting, family environments, and relational outcomes for millennials. Communication Studies, 65(4), 407-425. https://doi.org/10.1080/10510974.2013.811434

Virtue, E. E., \& Hinnant-Crawford, B. N. (2019). "We're doing things that are meaningful": Student perspectives of project-based learning across the disciplines. Interdisciplinary Journal of Problem-Based Learning, 13(2). https://doi.org/10.7771/1541-5015.1809

Vygotsky, L. S. (1978). Mind in society: The development of higher mental processes. Harvard University Press. 